\title{
How to have a Successful Dental Practice Part 7
}

\section{Harry Marget*}

Director and Dentist at East Bentleigh Dental Group, Melbourne, Australia

*Corresponding Author: Harry Marget, Director and Dentist at East Bentleigh Dental Group, Melbourne, Australia.

Received: June 19, 2019; Published: July 08, 2019

DOI: $10.31080 /$ ASDS.2019.03.0586

Probably the most commonly asked question the in the last 45 years of my dental practice and during the 20 years or so that I was a consultant to the dental industry both for professionals and the manufacturing industry was what defines a successful dental practice. But in actual fact the questions is much simpler than that because those people who had a plan succeeded in that plan and those who did not well we know the answer to that.

A simple rule of a primary school you fail to plan you plan to fail

So, what constitutes having a successful plan of course the answer that is incredibly simple the writing a fully orientated and fully subscribed business plan. Most dentist that I visited in the last 25 years since it is believed correctly or incorrectly that it was quite okay to simply hang a shingle and sit around and wait for work to roll in.

\section{Nothing could be further from the truth}

In 1974 when I started my first practice I decided that as I had learnt from others in my early years in working in the pubs and clubs that almost every business from the very basic to the more complex have business plan.

When I would sit down and discuss with dentists how to prepare content for the plan they will almost always throw their hands up and say I know nothing about that how can you help me to let us begin.

\section{Preparing content for your plan}

Keep your plan as short as possible as overly detailed business plans can be too cumbersome to use focus on the information that you need to know leave the fine details for operational and marketing plans to be attached at some later date after you have received technical advice from experts in the area or at this late as the product information guide one appendix.
Involve your team

One thing I have learnt is that your employees are both the success planning and planning success to get both insights and thereby into the plan involving employees will help you be successful and create a committed team planning together will also identify the provide useful benchmark to measure your performance

\section{Be realistic}

Try to view it realistic don't have an unrealistic sales forecasts try not to be everything to all men in the first few days and weeks of predicting always follow a predictable cash flow having place drastic cost-cutting if required and always remember to maintain your credibility to both lenders and dental supply companies or other interested parties as they will often see through optimistic plans that ignore weaknesses or threats.

Problem most importantly of all be professional even if your plan is intended for internal use only make sure that what you write and present is aimed at an outsider would cover on a plan and included contents page the page on section numbering one thing you must always do is start with an executive summary this works out very well when you go to dental supply companies all banks and other lenders to borrow large sums of money to allow you to proceed along the road to establishing your initial company or any others

Start with a brief history of your business when did it start trading what progress has made to date the business originally what is the current ownership structure.

In 1974 when I established East Bentleigh dental practice had been run by a sole practitioner and have retired from Army service and was only doing one dollar amalgams and three dollar extractions with $\$ 25$ dentures clearly a new plan needed to be placed to 
simply begin day one on 10 January 1974 providing molar endodontics et cetera would need to be integrated carefully and sensible providing crowns and the like these need to be integrated in a way that both the public the team on the existing staff would understand sounds easy but complex in its instruction.

Try and describe the product service that you are going to provide it may be difficult to suddenly start providing implants on a day-to-day basis if you have not made your team and your supplier aware of what you're going to try and do and most importantly in general what makes your prices service different what benefit is that offer what are its disadvantages and Haiti plan to develop the business.

\section{Next included your market and the competition}

That is your market defined the market it has local is it suburbia is it going to be Sydney-based is going to have an international flavour how large is each market segment what is your market share now what is it going to be in the future or the important trends are the shifts in population shifts in technology is market growth or changing tastes going to change the way you practice I want the reasons behind that trend what are the key drivers affecting each import market segment on how they going to affect you if suddenly you're not aware of any change.

Your customers try to work out the nature and distribution of your existing clientele try and find that the typical customer profile for each market segment the target you business of the turnover of more than 2 million or more or first-time buyers are the people in your area were professional people working in high level professionals are they heavily reliant on sales to large few customers how will market trends or financial trends within your area affect your business will a sudden changing of the order of workers make a difference what of the factory were closed down what is suddenly new shopping centre was to open up what if suddenly for high-rise apartment blocks built with an influx of new patients these sorts of decisions need to be catered for and allow for the future growth and development.

Your competitors define your principal competition what are the advantages and disadvantages of what they are offering a baby gets smaller more technical other better finance the new to have a better marketing plan then explain why customers would buy from you why your product or service instead of your competitive change and be careful of criticising or under messed around are estimating your competitors this could come back to bite you.

Specify your marketing and sales plan outline your proposed marketing and sales activities and include your positioning explain how your position your product or dental services in the marketplace we provide high quality and high price will you provide good value and durable you provide a specialist product with a particular feature on what unique selling features is your private hands and which of these features will concentrate on pricing policy.

Pricing policy probably the most difficult decision be what is your pricing policy explain how price sensitive your products or services are look at each product or market segment in turn identify where you make your profit and where that is the scope to increase margins or sales explain how you set your pricing policy.

Promotion happy promote each product or service how will each market segment react to what you have two offer what will be the optimum benefits will direct marketing work advertising PR relationships will use a radio campaign we use newspapers we use the web how will you make those profits and where is the scope to increase mansions or sales explain how you set your pricing policy according.

\section{Distribution}

Now most people do not have a product that they are going to sell rather a service I still believe this is important dentistry has changed over the last few years where many people now stock certain products and services within their surgeries as an add-on e.g. tooth makes it really do have a certain policy in place to deal with this rather than just so go and give Mrs Jones achievement to.

Sales methods analyse the cost efficiency of each of your selling methods for example are you going to work through television or radio are you going to use a direct sales force are you going to use agencies are you going to use television or radio and if you do use radio at what level and what market segment you don't aim need to also examine hidden costs such as management time.

In the second part of his article I will examine management of personnel, operations information systems financial performance or casts and something that is commonly referred to by the banks as swot analysis these are the strengths weaknesses opportunities and threats finally I will have a program in place to discuss how 
to go forward many of those topics will include income customers products services and human resources finally I'll provide information on how to update the plan as you go forward and also strategies can be used by dentist to constantly upgrade or downgrade things according to economic change.

I look forward to bring you further aspects to this vital part of managing a dental practice in future articles will stop finally.

I would like to express my gracious thanks to Mr Amos Lang for the opportunity to present these articles through his highly respected and well distributed magazine.

Volume 3 Issue 8 August 2019

(C) All rights are reserved by Harry Marget. 